\title{
Piperazine ferulate ameliorates the development of diabetic nephropathy by regulating endothelial nitric oxide synthase
}

\author{
YONG-YU YANG ${ }^{1,2}$, LING-XING SHI $^{3}$, JIAN-HE LI $^{1,2}$, LIANG-YUAN YAO $^{2,4}$ and DA-XIONG XIANG ${ }^{1,2}$ \\ ${ }^{1}$ Department of Pharmacy; ${ }^{2}$ Hunan Provincial Engineering Research Center of Translational Medical and Innovative Drug, \\ The Second Xiangya Hospital of Central South University, Changsha, Hunan 410011; ${ }^{3}$ Department of Pharmacology, \\ Changsha Medical University, Changsha, Hunan 410219; ${ }^{4}$ Hunan Qianjin Xiangjiang Pharmaceutical Industry Co., Ltd., \\ Zhuzhou, Hunan 412000, P.R. China
}

Received July 5, 2018; Accepted December 20, 2018

DOI: $10.3892 / \mathrm{mmr} .2019 .9875$

\begin{abstract}
Diabetic nephropathy (DN) is among the most common complications of diabetes mellitus. The disorder is associated with a decrease in the activity of the nitric oxide synthase/nitric oxide system. Piperazine ferulate (PF) is widely used for the treatment of kidney disease in China. The aim of the present study was to examine the effects of PF on streptozotocin (STZ)-induced DN and the underlying mechanism of this process. STZ-induced diabetic mice were intragastrically administered PF (100, 200 and $400 \mathrm{mg} / \mathrm{kg} /$ body weight/day) for 12 weeks. At the end of the treatment period, the parameters of 24-h albuminuria and blood urea nitrogen, creatinine and oxidative stress levels were measured. Hematoxylin and eosin staining, periodic acid-Schiff staining and electron microscopy were used to evaluate the histopathological alterations. mRNA and protein expression of endothelial nitric oxide synthase (eNOS) were measured by quantitative polymerase chain reaction and western blotting, respectively. PF significantly decreased blood urea nitrogen and creatinine levels and 24-h albuminuria, and it alleviated oxidative stress, improved glomerular basement membrane thickness and caused an upregulation in eNOS expression and activity levels in diabetic mice. In addition, high glucose decreased eNOS expression levels, whereas PF caused a reversal in the nitric oxide (NO) levels of glomerular endothelial cells. The present results suggested that PF exhibited renoprotective effects on DN. The
\end{abstract}

Correspondence to: Mrs. Liang-Yuan Yao, Hunan Qianjin Xiangjiang Pharmaceutical Industry Co., Ltd., 1 Jinlong East Road, Zhuzhou, Hunan 412000, P.R. China

E-mail: yaoliangyuan733@163.com

Dr Da-Xiong Xiang, Department of Pharmacy, The Second Xiangya Hospital of Central South University, 139 Renminzhong Road, Changsha, Hunan 410011, P.R. China

E-mail: xiangdaxiong@csu.edu.com

Key words: piperazine ferulate, diabetic nephropathy, glomerular endothelial cell, endothelial nitric oxide synthase mechanism of its action was associated with the regulation of eNOS expression and activity.

\section{Introduction}

Diabetic nephropathy (DN) is among the major diabetic microvascular complications and the leading cause of end-stage renal disease (ESRD). According to a report by the International Diabetes Federation in 2017, 425 million adults have been recorded as having diabetes worldwide (1). A high percentage of patients with diabetes mellitus (up to $30 \%$ ) develop DN (2). Various factors are involved in the development of DN. Nitric oxide (NO) is a gaseous molecule that is also known as endothelium-derived relaxing factor and has proven functional in the development of DN (3). In particular, NO may be involved in the progressive alteration of glomerular hemodynamics in diabetic subjects $(4,5)$. The production of $\mathrm{NO}$ is catalyzed by the enzyme NO-synthase. A total of three NO-synthase (NOS) enzymes, namely endothelial NOS (eNOS), neuronal NOS and inducible NO comprise the major isoforms of this enzyme family (6). Several studies have demonstrated that eNOS depletion can accelerate nephropathy progression in diabetic mice $(7,8)$. Therefore, pharmacological improvement of impaired eNOS function or NO production in the glomerular endothelium may mitigate the progression of DN.

Piperazine ferulate (PF) is a derivative of ferulic acid, which has been used in China for the treatment of different types of glomerular disease, including nephritis and nephritic syndrome. A clinical study performed in children with immunoglobulin (Ig)A nephropathy reported that PF tablets combined with eucalyptol-limonene-pinene enteric soft capsules were safe and effective for the treatment of this type of nephropathy (9). It has also been reported that PF can inhibit TGF- $\beta 1$-induced renal interstitial fibroblast activation (10) and synthesis of the extracellular matrix in TGF- $\beta 1$-induced mesangial cells (11). However, the renoprotective effect of PF in DN and the underlying mechanism of its action have not yet been investigated.

In the present study, whether PF exerts a preventive effect against DN was investigated and the underlying mechanism of its action was also investigated. The data indicated that PF delayed the development of DN and the mechanism of action was associated with normalized expression and activity of eNOS. 


\section{Materials and methods}

Materials. MTT, streptozotocin (STZ) and dimethyl sulfoxide (DMSO) were obtained from Beijing Solarbio Biotechnology Co., Ltd., (Beijing, China). N-nitro-L-arginine methylester (L-NAME), NO and nitric oxide synthase (NOS) assay kits were purchased from Beyotime Institute of Biotechnology (Haimen, China). PF was obtained from Hunan Qianjin Xiangjiang Pharmaceutical Industry Co., Ltd. (Zhuzhou, China). A mouse albumin ELISA kit was purchased from Abcam (Cambridge, UK; cat. no. ab108791). Polyclonal rabbit anti-mouse antibodies specific for eNOS (cat. no. 9572) and p-eNOS ${ }^{1177}$ (cat. no. 9571) were obtained from Cell Signaling Technology Inc., (Danvers, MA, USA). A $\beta$-actin antibody (cat.no.BM0626) was purchased from Wuhan Boster Biological Technology, Ltd., (Wuhan, China). Creatinine (cat. no. C011-2) and blood urea nitrogen (BUN, cat. no. C013-2) assay kits were obtained from Jiancheng Technology Co., Ltd (Nanjing, China). The glucose assay kit (cat. no. 361500) was purchased from Shanghai Rongsheng Biotechnology Co., Ltd. (Shanghai, China). All other chemicals were of analytical grade.

Animals. A total of 75 C57BL/6J male mice (aged 8 weeks, 19-22 g) were obtained from the Experimental Animal Center of Silaikejingda (Changsha, China). The mice were maintained in a $12 \mathrm{~h} \mathrm{light/dark} \mathrm{cycle} \mathrm{at} 22 \pm 2^{\circ} \mathrm{C}$ and $50-60 \%$ humidity, with free access to a standard diet and tap water. The animals underwent an acclimatization period of 7 days prior to the experimental conduct. The animal protocol was approved by the Ethics Committee of Animal Experiments of the Central South University and was performed in accordance with the Guide for the Care and Use of Laboratory Animals.

Experimental design. Initially, animals were randomly divided into two groups: A control group $(\mathrm{n}=15)$ and a model group $(n=60)$. The model group mice were intraperitoneally injected for 5 consecutive days with STZ $(65 \mathrm{mg} / \mathrm{kg}$ body weight). This chemical was dissolved in citrate buffer $(0.1 \mathrm{M}$, $\mathrm{pH} 4.0$ ) and administered to the animals following overnight fasting as described previously (12). The control group mice were injected with citrate buffer solution (0.1 M, pH 4.0). The blood glucose concentration in mice was monitored for $48 \mathrm{~h}$ following the injection and was measured every 3 days thereafter. A blood glucose level of $>16.7 \mathrm{mmol} / \mathrm{l}$ indicated successful induction of diabetes. Following one week of animal maintenance, the diabetic mice were randomly divided into four groups: A model control group $(\mathrm{n}=15)$, a low PF dosage group (PF-L; n=15), a medium PF dosage group (PF-M; $n=15$ ) and a high PF dosage group (PF-H; $n=15)$. The normal control and model control groups were provided with $0.5 \%$ sodium carboxymethylcellulose (CMC-Na), whereas the experimental mice received PF suspended in 0.5\% CMC-Na at a dosage of 100,200 and $400 \mathrm{mg} / \mathrm{kg}$ body weight once a day. Following treatment for 12 weeks, the 24-h urine was collected from each animal using metabolic cages. At the termination of the study, all mice were anaesthetized using sodium pentobarbital ( $50 \mathrm{mg} / \mathrm{kg}$ body weight), then the blood was collected. Finally, mice were sacrificed by exsanguination and the kidney tissue was quickly removed. Animal death was confirmed by comprehensively examining the vital signs of animal, including lack of breathing, lack of a heartbeat, reflexes and the presence of rigor mortis.

Serum and urine measurements. Urinary albuminuria was determined with the commercially available ELISA kit. The parameters of blood glucose, creatinine and BUN were also measured using respective kits following the manufacturer's protocols.

Cell culture. Primary human glomerular endothelial cells (GEnCs) were obtained from ScienCell Research Laboratories, Inc., (San Diego, CA, USA) and were maintained in endothelial cell medium (ECM, ScienCell Research Laboratories, Inc.) containing 5\% fetal bovine serum (FBS; ScienCell Research Laboratories, Inc.), $1 \%$ penicillin/streptomycin and $1 \%$ endothelial cell growth factor (ScienCell Research Laboratories, Inc.). All experiments were performed using GEnCs at passages 3-6. The cells were cultured at $37^{\circ} \mathrm{C}$ in $5 \% \mathrm{CO}_{2}$.

Histological evaluation. The kidney tissues of the mice were fixed at $4^{\circ} \mathrm{C}$ in $4 \%$ paraformaldehyde for $24 \mathrm{~h}$ and then embedded in paraffin wax. The paraffin-embedded kidney tissues were cut into $3-\mu \mathrm{m}$ slices and the sections were stained using routine hematoxylin and eosin (H\&E) and periodic acid-Schiff (PAS) staining methods. For H\&E staining, sections were stained in hematoxylin for $3 \mathrm{~min}$ and eosin for $1 \mathrm{~min}$ at room temperature. For PAS staining, sections were stained with periodic acid solution for $20 \mathrm{~min}$ and Schiff's reagent at $37^{\circ} \mathrm{C}$ for $30 \mathrm{~min}$ in the dark, then subsequently counterstained with hematoxylin for 2 min. Following staining, the histopathological changes in the kidney tissue slices were observed under light microscopy at $\mathrm{x} 400$ magnification. The H\&E-stained sections were used for glomerular area studies. The surface area of the glomerular sections derived from each animal was determined by digital image analysis using ImageJ $1.37 \mathrm{c}$ software (National Institutes of Health, Bethesda, MD, USA). PAS staining was performed in order to evaluate the degree of glomerulosclerosis (glomerulosclerosis index). Semiquantitative scoring of glomerulosclerosis was performed using a five-grade method as described previously (13). Briefly, the degree of sclerosis was graded as follows: $0=$ no sclerosis; $1=$ sclerosis involving $<25 \%$ of the area examined; $2=$ sclerosis involving $25-50 \%$ of the area examined; $3=$ sclerosis involving 50 to $75 \%$ of the area examined; $4=$ sclerosis involving $>75 \%$ of the area examined. The glomerulosclerosis index was calculated using the following formula: Glomerulosclerotic index $=1 \times \mathrm{N}_{1}+2 \mathrm{xN}_{2}+3 \mathrm{xN}_{3}+4 \times \mathrm{N} 4 / \mathrm{N}_{0}+\mathrm{N}_{1}+\mathrm{N}_{2}+\mathrm{N}_{3}+\mathrm{N}_{4}$, where $\mathrm{N}$ is the number of glomeruli in each grade of sclerosis.

Electron microscopy analysis. Cortical kidney tissues were fixed with $2.5 \%$ glutaraldehyde at room temperature for $24 \mathrm{~h}$ and then post-fixed in $1 \%$ osmium tetroxide at $4^{\circ} \mathrm{C}$ for $2 \mathrm{~h}$ in the dark. The tissue samples were dehydrated in graded ethanol and treated with propylene oxide for $3 \mathrm{~h}$ at room temperature. Subsequently, the sections were embedded in EMbed 812 resin (Thermo Fisher Scientific, Inc., Waltham, MA, USA) and polymerized at $60^{\circ} \mathrm{C}$ for $48 \mathrm{~h}$. The ultrathin sections $(60-80 \mathrm{~nm})$ were stained with $1 \%$ uranyl acetate for $10 \mathrm{~min}$, followed by $2 \%$ lead citrate buffer for $2 \mathrm{~min}$ at $37^{\circ} \mathrm{C}$. The structure of the glomerular endothelial cell layer 
was captured via transmission electron microscopy (Hitachi High-Tech7700).

Assessment of cellular viability. Cellular viability was measured by MTT assay. Briefly, GEnCs were cultured in a 96-well plate and treated with different concentrations of PF for $24 \mathrm{~h}$. MTT was added to each well, and GEnCs were cultured at $37^{\circ} \mathrm{C}$ for $3 \mathrm{~h}$. The medium containing MTT was discarded and the formazan was dissolved in $150 \mu 1$ dimethyl sulfoxide. The absorbance was measured at $490 \mathrm{~nm}$ using a microplate reader. Cellular viability was expressed as the relative percentage of the absorbance value of PF-treated cells compared with that of the control cells.

Evaluation of intracellular eNOS level. GEnCs were seeded in 6 -well plates at a density of $1 \times 10^{4}$ per $\mathrm{cm}^{2}$. When the confluence reached at 50-60\%, the medium was replaced with low sugar Dulbecco's modified Eagle's medium (Hyclone; GE Healthcare Life Sciences, Logan, UT, USA) containing $10 \%$ FBS. Then, the cells randomly divided into 5 groups: Control group (normal glucose, $5.5 \mathrm{mM}$ glucose), PF group $(100 \mu \mathrm{M}$ $\mathrm{PF}$ ), high glucose group (30 mM D-glucose, $\mathrm{HG}$ ), $\mathrm{PF}+\mathrm{HG}$ group $(100 \mu \mathrm{M} \mathrm{PF}+30 \mathrm{mM} \mathrm{D}$-glucose) and mannitol group (24.5 mM D-mannitol plus $5.5 \mathrm{mM}$ glucose). GEnCs were pre-incubated with $\mathrm{PF}(100 \mu \mathrm{M})$ for $4 \mathrm{~h}$, then subjected to $\mathrm{HG}$ for $24 \mathrm{~h}$. D-mannitol was used as an osmotic control for the HG. Following treatment, the cells were harvested and the mRNA and protein of eNOS were detected.

Assessment of NO expression levels and NOS activity. Total NO production and NOS activity were measured using NO and NOS kits, respectively, according to the manufacturer's protocols. The tissues from the mice were homogenized in Cell and Tissue Lysis Buffer for NO assay (cat. no. S3090; Beyotime Institute of Biotechnology) and used for NO or NOS activity detection. The protein concentration was quantified by the bicinchoninic acid (BCA) method in accordance with the manufacturer's protocol. The optical density value of each sample was read by a microplate reader at $550 \mathrm{~nm}$. The resulting data regarding NO expression and NOS activity were normalized to the total amount of protein in the samples.

Determination of kidney oxidative stress. Malondialdehyde (MDA; cat. no. S0131) levels and superoxide dismutase (SOD; cat. no. S0109), glutathione peroxidase (GSH-Px; cat. no. S0056) and catalase activities (cat. no. S0051) were determined in the renal tissue sample homogenates using commercially available kits (Beyotime Institute of Biotechnology) according to the manufacturer's protocols.

Evaluation of intracellular NO levels with DAF-2 DA. GEnCs were seeded into 24 -well culture plates at a density of $1 \times 10^{4}$ per $\mathrm{cm}^{2}$. Following cell treatment, the supernatants were removed and subsequently washed 3 times with HEPES buffer at room temperature. The cells were incubated with DAF-FM DA $(5 \mu \mathrm{M})$ for $20 \mathrm{~min}$ in the dark at $37^{\circ} \mathrm{C}$ and rinsed 3 times with HEPES buffer (Beijing Dingguo Changsheng Biotechnology Co., Ltd., Beijing, China). The fluorescence within the cells was detected at $\lambda_{\mathrm{ex}}=495$ and $\lambda_{\mathrm{em}}=515 \mathrm{~nm}$ with a fluorescence microscope (Zeiss AG, Oberkochen, Germany).
Gene analysis. Total RNA was extracted from cultured cells and kidney tissues using TRIzol reagent (Invitrogen; Thermo Fisher Scientific, Inc.) and quantified by spectrophotometry (NanoDrop Technologies, Wilmington, DE, USA). cDNA was produced by RNA using a reverse transcription kit (Takara Biotechnology Co., Ltd., Dalian, China) in a $10 \mu \mathrm{l}$ reaction system containing $2 \mu \mathrm{l} 5 \mathrm{X}$ PrimeScript buffer, $0.5 \mu 1$ PrimeScript RT enzyme mix I, $0.5 \mu 1$ oligo dT primers $(50 \mu \mathrm{M}), 0.5 \mu \mathrm{l}$ random 6 mers $(100 \mu \mathrm{M}), 2 \mu \mathrm{l}$ total RNA (400 ng), $4.5 \mu \mathrm{l}$ RNase free $\mathrm{dH}_{2} \mathrm{O}_{2}$. Reverse transcription reaction conditions were as follows: $37^{\circ} \mathrm{C}$ for $15 \mathrm{~min}$ and $85^{\circ} \mathrm{C}$ for $5 \mathrm{sec}$. Quantitative polymerase chain reaction (qPCR) was performed using SYBR Green PCR mix (Takara Biotechnology Co., Ltd.) on a LightCycler 96 (Roche Applied Science, Mannheim, Germany). Thermocycling conditions were as follows: Denaturing at $95^{\circ} \mathrm{C}$ for $30 \mathrm{sec}$ and 45 cycles of $95^{\circ} \mathrm{C}$ for $5 \mathrm{sec}$ and $60^{\circ} \mathrm{C}$ for $30 \mathrm{sec}$. The $2^{-\Delta \Delta \mathrm{Cq}}$ method (14) was used to calculate relative gene expression. Gene expression levels were normalized to $\beta$-actin. The forward and reverse primer sequences used for eNOS and $\beta$-actin were as follows: Forward, 5'-AGCGGCTGGTACATGAGTTC-3' and reverse, 5'-ACAGGGATGAGGTTGTCCTG-3', and forward, 5'-ACT GCTCTGGCTCCTAGCAC-3' and reverse, 5'-ACATCTGCT GGAAGGTGGAC-3', respectively.

Protein analysis. Kidney tissue and harvested cells were lysed on ice with radioimmunoprecipitation assay (RIPA) buffer (Beyotime Institute of Biotechnology) and the lysates were centrifuged at $12,000 \mathrm{xg}$ for $15 \mathrm{~min}$ at $4^{\circ} \mathrm{C}$. The protein concentration was measured using a BCA assay kit (Beyotime Institute of Biotechnology). A total of $35 \mu \mathrm{g}$ protein/lane was loaded on an $10 \%$ SDS-PAGE gel for electrophoresis and then transferred to a nitrocellulose membrane (EMD Millipore, Billerica, MA, USA). The blots were blocked in TBS-T $(0.1 \%$ Tween 20) buffer with 5\% skimmed milk at room temperature for $1 \mathrm{~h}$ and then incubated overnight with primary antibodies against e-NOS (1:500), phopho-Ser ${ }^{177}$ eNOS (1:200) and $\beta$-actin (1:500) at $4^{\circ} \mathrm{C}$. The blots were then incubated with horseradish peroxidase-conjugated secondary antibodies $(1: 5,000)$ for $1 \mathrm{~h}$ at room temperature. The immunoblots were visualized by enhanced chemiluminescence (Beyotime Institute of Biotechnology) and quantified with ImageJ software. The protein expression levels were normalized to $\beta$-actin.

Statistical analyses. All data were presented as the mean \pm standard error of the mean of three experimental repeats. SPSS 18.0 software (SPSS, Inc., Chicago, IL, USA) was used to analyze the data. One-way analysis of variance and the subsequently Student-Newman-Keuls' test was used to determine the differences among groups. $\mathrm{P}<0.05$ was considered to indicate a statistically significant difference.

\section{Results}

Role of PF in the progression of $D N$. The model control group and $\mathrm{PF}$ group mice exhibited significantly $(\mathrm{P}<0.01)$ lower body weight compared with the control mice. Pretreatment with different doses of PF did not increase body weight in diabetic mice, compared with the model control 

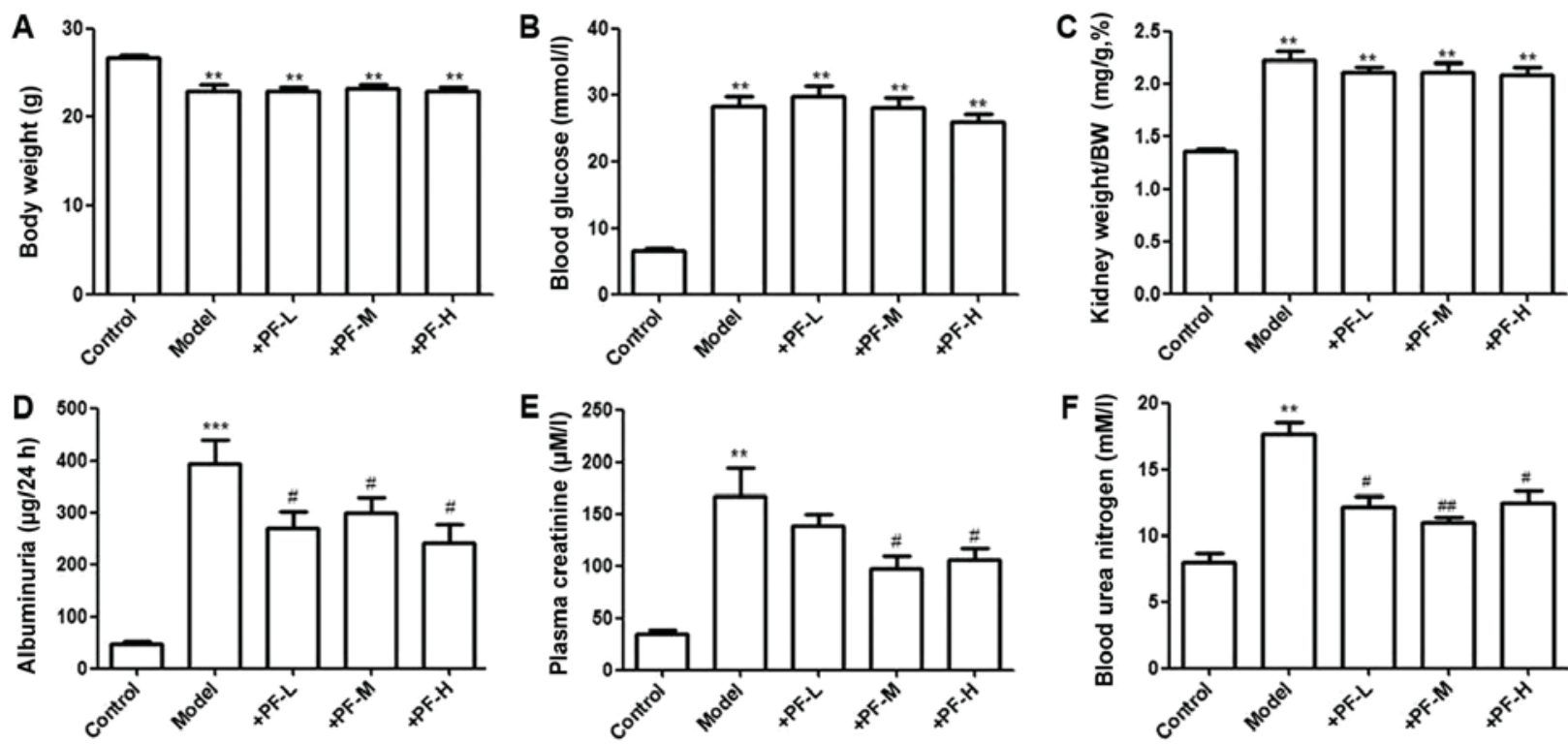

Figure 1. PF prevents the development of diabetic nephropathy. (A) Effect of PF on body weight. (B) Blood glucose levels. (C) Ratio of kidney weight/BW. (D) Degree of albuminuria $(24 \mathrm{~h})$. (E) Plasma creatinine levels. (F) Blood urea nitrogen levels. All values are expressed as the mean \pm standard error of the mean. $\mathrm{n}=15,{ }^{* *} \mathrm{P}<0.01$ and ${ }^{* * *} \mathrm{P}<0.001$ vs. the control, ${ }^{\#} \mathrm{P}<0.05$ and ${ }^{\# \#} \mathrm{P}<0.05$ vs. the model. PF, Piperazine ferulate; L, low; M, medium; H, high; BW, body weight.

group (Fig. 1A). The parameters of blood glucose level and ratio of kidney weight to body weight were significantly increased in the model group and PF group, compare with the control $(\mathrm{P}<0.01)$. The elevated levels of blood glucose and the increased ratio of kidney weight to body weight in diabetic mice were not attenuated by different PF treatments for 12 weeks (Fig. 1B and C). In the model control group, the parameters of albuminuria and creatinine and blood urea nitrogen levels were significantly increased $(\mathrm{P}<0.01)$, and $\mathrm{PF}$ treatment at 200 and $400 \mathrm{mg} / \mathrm{kg}$ body weight was capable of decreasing significantly $(\mathrm{P}<0.05)$ these effects in diabetic mice (Fig. 1D-F).

Effect of PF on oxidative stress parameters. Oxidative stress markers, including CAT, SOD, GSH and MDA, have been associated with the development of diabetic nephropathy. The effects of PF on these antioxidant parameters were investigated in STZ-induced diabetic mice at the end of the 12-week treatment period (Fig. 2). The model group mice indicated a significant $(\mathrm{P}<0.05)$ decrease in the activities of CAT, SOD and GSH-Px and an increase in the MDA levels of the kidney tissue samples compared with those detected in the control samples. Furthermore, treatment of diabetic mice with medium and high doses of PF significantly $(\mathrm{P}<0.05)$ reversed the decrease in SOD, CAT and GSH-Px activities (Fig. 2A-C). Concomitantly, PF significantly attenuated the increase detected in the MDA levels $(\mathrm{P}<0.05$; Fig. 2D) of the kidney tissue samples, compared with those of the control group.

Histological changes. Representative images of kidney tissue sections that were stained with H\&E and PAS are presented in Fig. 3. H\&E-staining of the kidney tissues derived from model control mice indicated significantly increased glomerular area $(\mathrm{P}<0.05)$ and thickening of Bowman's capsules compared with those of the control mice (Fig. 3A and C). However, treatment of diabetic mice with 200 and $400 \mathrm{mg} / \mathrm{kg}$ PF significantly $(\mathrm{P}<0.05)$ attenuated the increased glomerular area and restored the renal cytoarchitecture. PAS staining results indicated that model mice exhibited increased glomerular mesangial matrix hyperplasia, basement membrane thickness and the glomerulosclerotic index. The treatment of diabetic mice with PF significantly attenuated mesangial expansion and basement membrane thickness, and reduced the glomerulosclerotic index $(\mathrm{P}<0.05$; Fig. 3B and $\mathrm{D})$. This result suggested that $\mathrm{PF}$ could delay the progression of $\mathrm{DN}$.

PF increases eNOS expression and NO levels. The results obtained by electron microscopy indicated that PF treatment further decreased diabetes-induced glomerular basement membrane thickening and endothelial injury (Fig. 4A). Previous studies have reported that inhibition of NO production aggravates the development of DN (15-17). The levels of $\mathrm{NO}$ in renal tissues were assessed in order to evaluate whether $\mathrm{PF}$ exerts renoprotective effects. NO levels in renal tissues of model control group were significantly $(\mathrm{P}<0.05)$ decreased compared with the control group (Fig. 4B), whereas treatment of mice with PF restored these alterations. qPCR and western blotting were employed to analyze eNOS expression levels in the renal tissues of each animal group. The data indicated a decrease in the mRNA and protein levels in the kidney tissues of model control mice compared with those of the normal control mice (Fig. $4 \mathrm{C}$ and $\mathrm{E}$ ). The mice treated with $\mathrm{PF}$ exhibited a significant increase in the expression levels of eNOS $(\mathrm{P}<0.05)$, compared with those in the model control group (Fig. 4C, E and F). Subsequently, the activity of NOS in the renal tissues of each group of mice was detected. PF increased the ability of NOS and consequently NO production compared with that of the model control group (Fig. 4D). To further elucidate the mechanism responsible for the induction of eNOS activity, the effects of PF on the levels of eNOS-ser ${ }^{177}$ phosphorylation in mouse renal tissues were evaluated. PF 

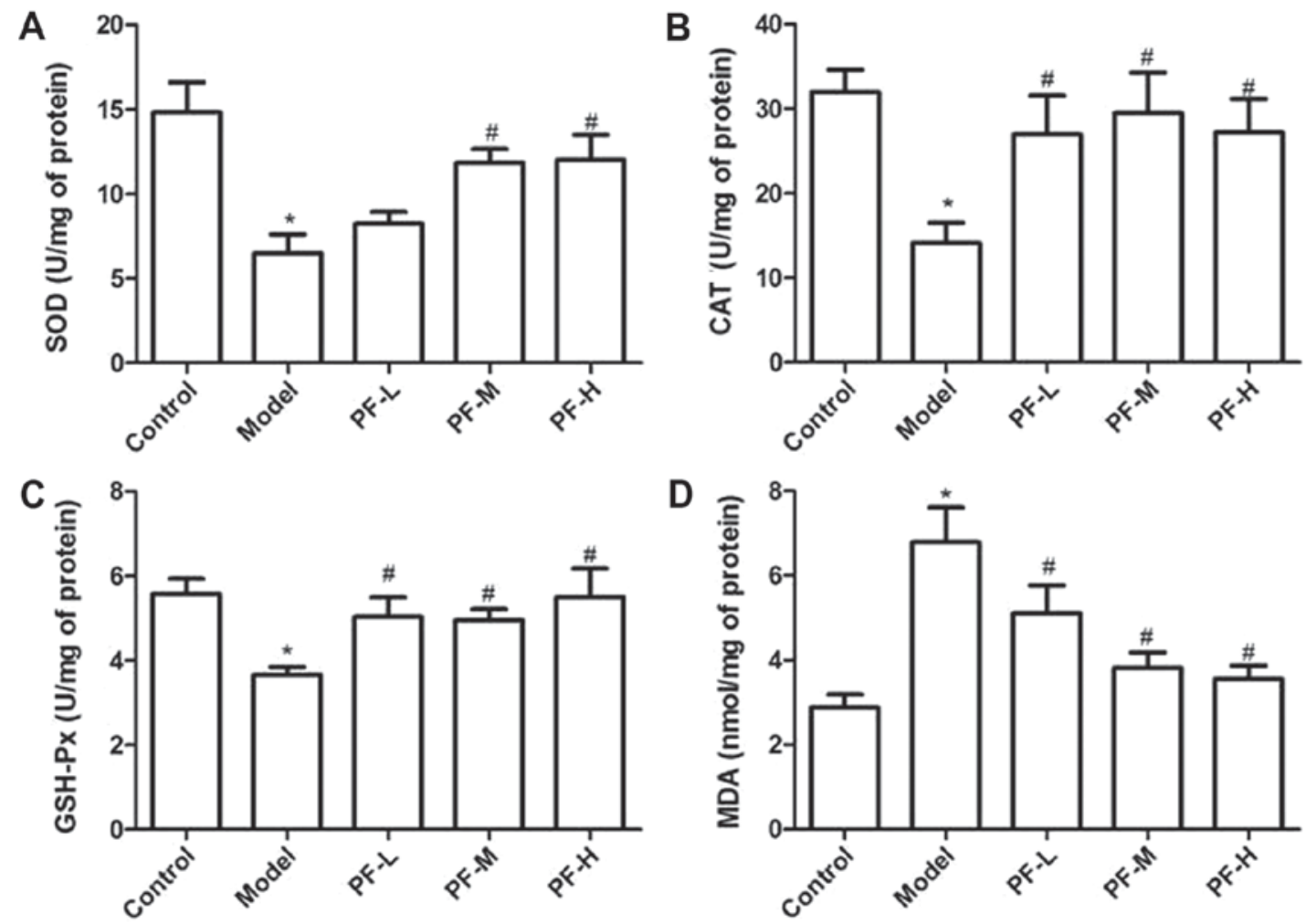

Figure 2. Effect of PF on antioxidant parameters in kidney tissues of streptozotocin-induced diabetic mice at the end of the 12-week period. (A) SOD activity levels. (B) CAT activity levels. (C) GSH-Px activity levels. (D) MDA levels. All values are expressed as the mean \pm standard error of the mean. "P<0.05 vs. the control, ${ }^{\text {PP}}<0.05$ vs. the model. PF, Piperazine ferulate; L, low; M, medium; H, high; MDA, malondialdehyde; CAT, catalase; SOD, superoxide dismutase; GSH-Px, glutathione-peroxidase.
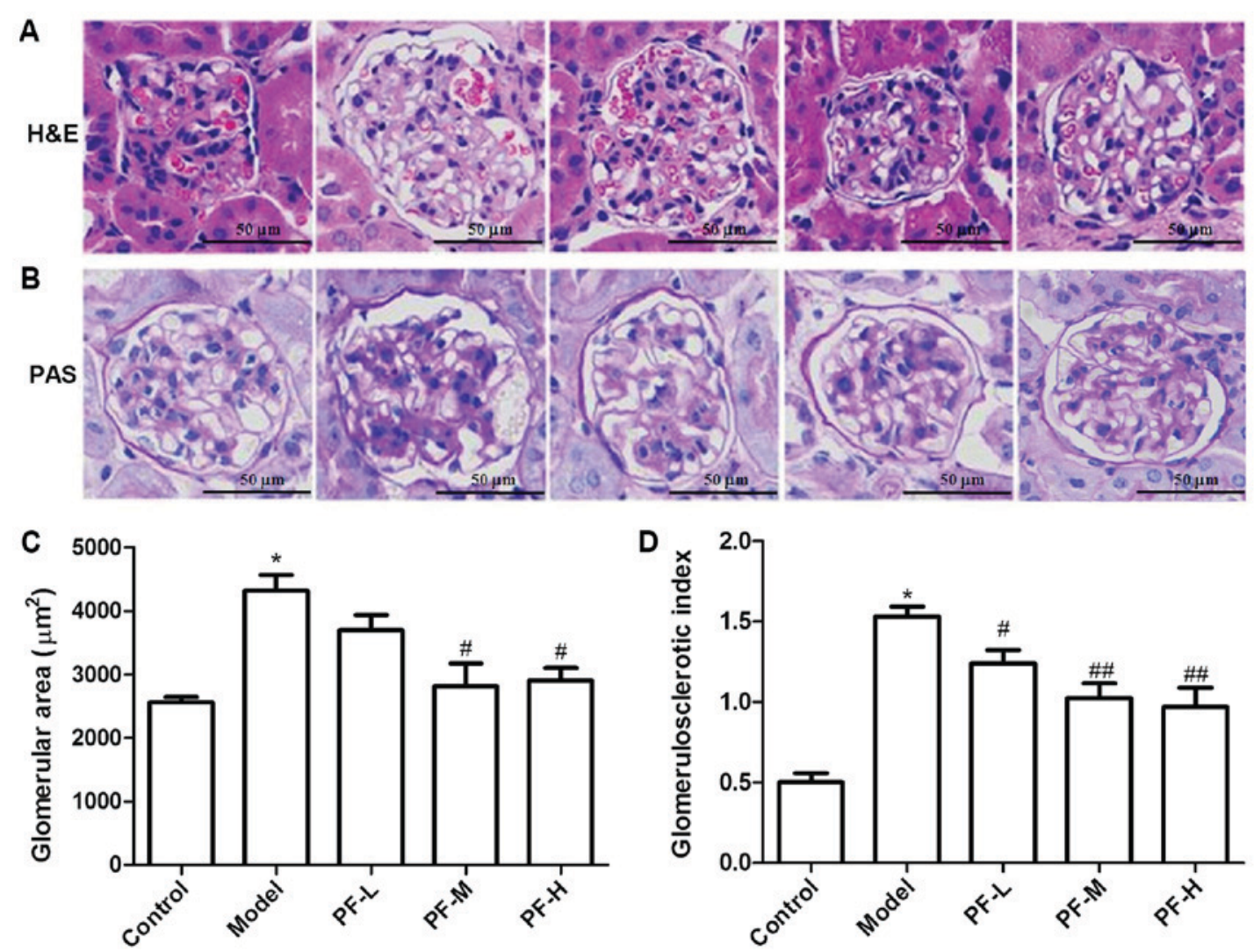

Figure 3. Effect of PF on morphological alterations of kidney tissues. (A) Representative photomicrographs (at original x400 magnification) of glomeruli from control mice, model mice and PF-treated diabetic nephropathy mice. Bars: $50 \mu \mathrm{m}$. (B) Glomerular mesangial expansion in diabetic mice. (C) Glomerular surface area. (D) Glomerulosclerotic index. All values are expressed as the mean \pm standard error of the mean. ${ }^{*} \mathrm{P}<0.05$ vs. the control, ${ }^{\#} \mathrm{P}<0.05$ and ${ }^{\# \#} \mathrm{P}<0.05$ vs. the model. PF, Piperazine ferulate; L, low; M, medium; H, high; H\&E, hematoxylin and eosin; PAS, periodic acid-Schiff. 
A
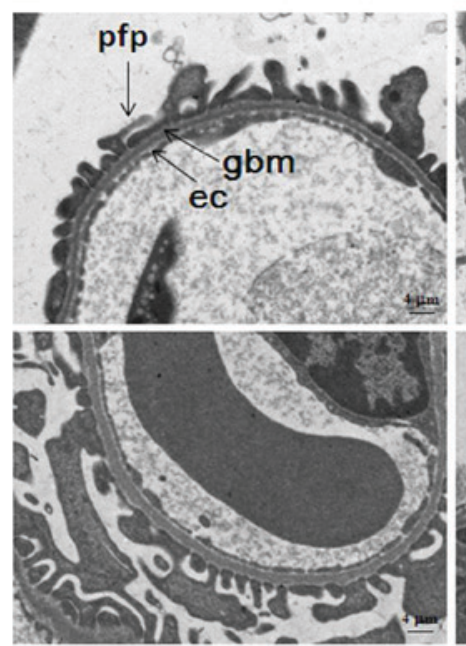
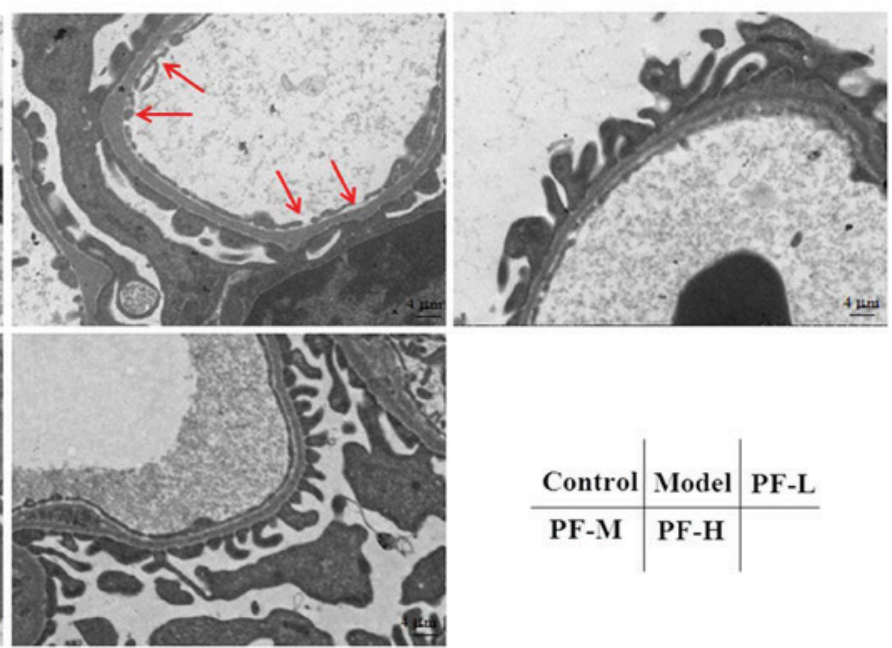

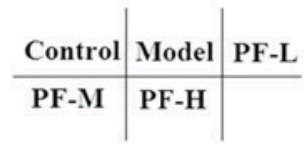

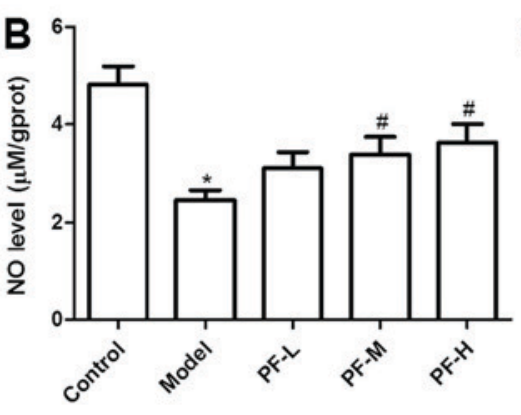

E
C

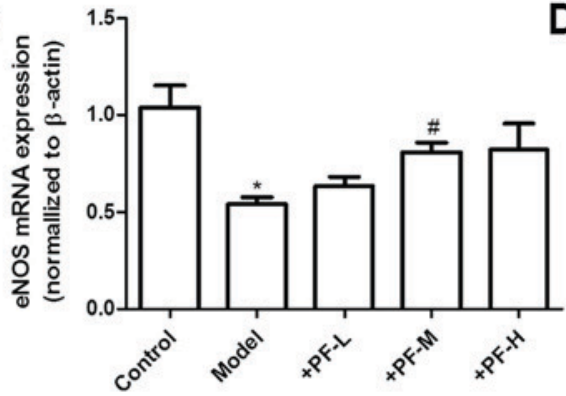

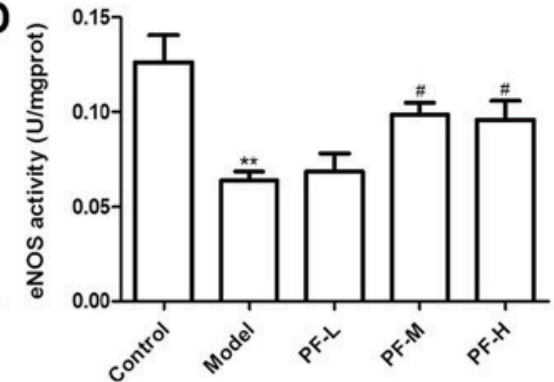

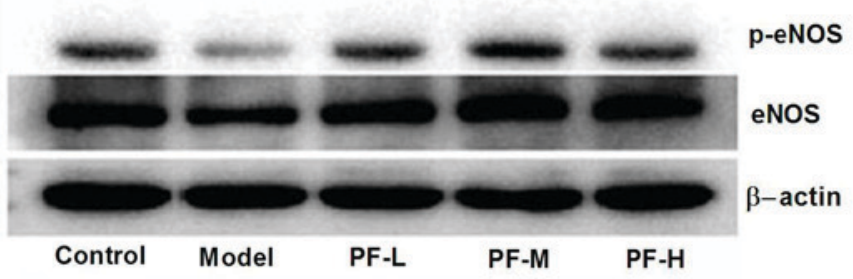

$\mathbf{F}$

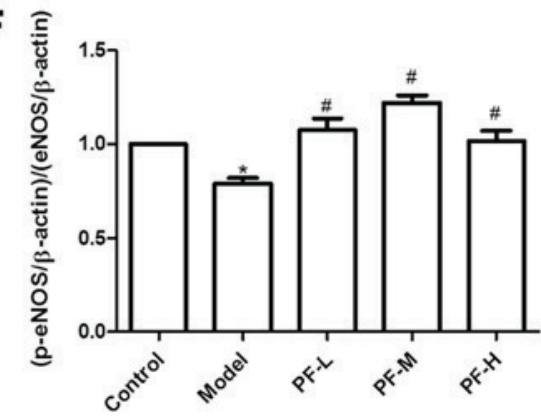

Figure 4. Diabetic mice exhibit decreased eNOS/NO levels and PF reverses this condition in renal tissues. (A) Electron micrographs of glomerular capillary wall (at original x 5,000 magnification). Red arrows indicate endothelial cell damage. ec, endothelial cell; gbm, glomerular basement membrane; pfp, podocyte foot process. Scale bars: $4 \mu \mathrm{m}$. (B) NO levels in renal tissues. (C) eNOS mRNA expression levels in kidney tissues. (D) Effect of PF on NOS activity levels. (E) Representative protein expression levels. (F) p-eNOS/eNOS level. ${ }^{*} \mathrm{P}<0.05,{ }^{* *} \mathrm{P}<0.01$ vs. the control, ${ }^{\#} \mathrm{P}<0.05$ vs. the model. PF, Piperazine ferulate; L, low; M, medium; H, high; NO, nitric oxide; eNOS, endothelial nitric oxide synthase; p, phosphorylated.

further increased eNOS-ser ${ }^{1177}$ phosphorylation levels in the kidney tissue of diabetic mice (Fig. 4E and F). These results suggested that PF could affect the expression levels and activity of eNOS.

PF improves NO levels in the HG-induced cell model. Previous studies have demonstrated that dysfunction of GEnCs is a key factor in the progression of DN (18-20). The effect of PF on NO production was further evaluated in a high glucose (HG)-treated GEnC model. Initially, the potential effects of PF on GEnC viability was assessed via MTT assay. The results indicated that different concentrations (12.5-200 $\mu \mathrm{M})$ of PF exerted no effect on cell viability (Fig. 5A). In order to investigate the effect of PF on eNOS expression levels in vitro, GEnCs were treated with $\mathrm{HG}$ (30 $\mathrm{mM})$ for $24 \mathrm{~h}$ and mannitol $(24.5 \mathrm{mM}$ mannitol plus
$5.5 \mathrm{mM}$ glucose) was used as an osmotic control for the HG. As expected, HG significantly decreased eNOS mRNA and protein expression levels $(\mathrm{P}<0.05)$, while mannitol exhibited no effect on either of these markers. In contrast to these observations, preincubation of GEnCs with PF $(100 \mu \mathrm{M})$ resulted in an attenuation of the decreased levels of eNOS mRNA and protein compared with those of the HG group $(\mathrm{P}<0.05$; Fig. $5 \mathrm{~B}$ and $\mathrm{C})$. Whether $\mathrm{PF}$ affects $\mathrm{NO}$ production in GEnCs by regulating eNOS activity was further investigated. GEnCs were preincubated with or without L-NAME, a specific inhibitor of eNOS, for $30 \mathrm{~min}$ prior to incubation of $\mathrm{PF}$ at $100 \mu \mathrm{M}$ for $4 \mathrm{~h}$ and subsequently treated with HG. A decrease in the NO levels of the $\mathrm{LAMN}+\mathrm{PF}+\mathrm{HG}$ group was noted compared with that of the $\mathrm{PF}+\mathrm{HG}$ group (Fig. 5D). These results further indicated that PF affects the concentration of NO by regulating eNOS activity. 
A

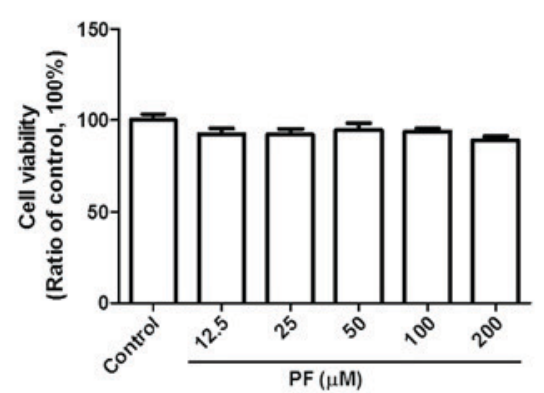

D

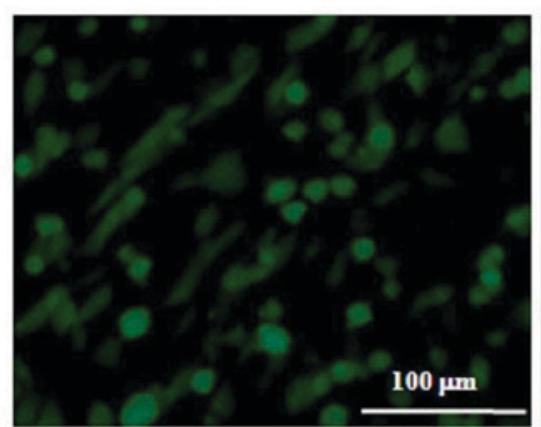

Control

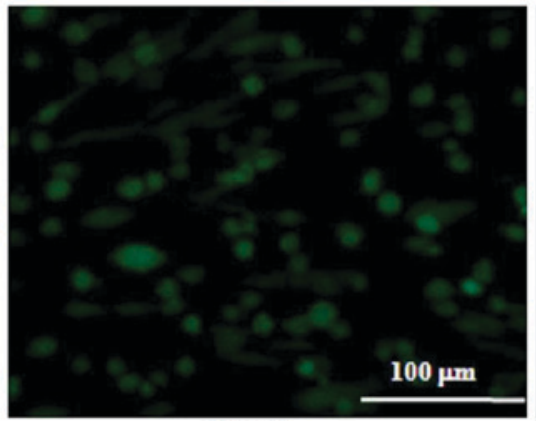

$\mathrm{PF}+\mathrm{HG}$
B
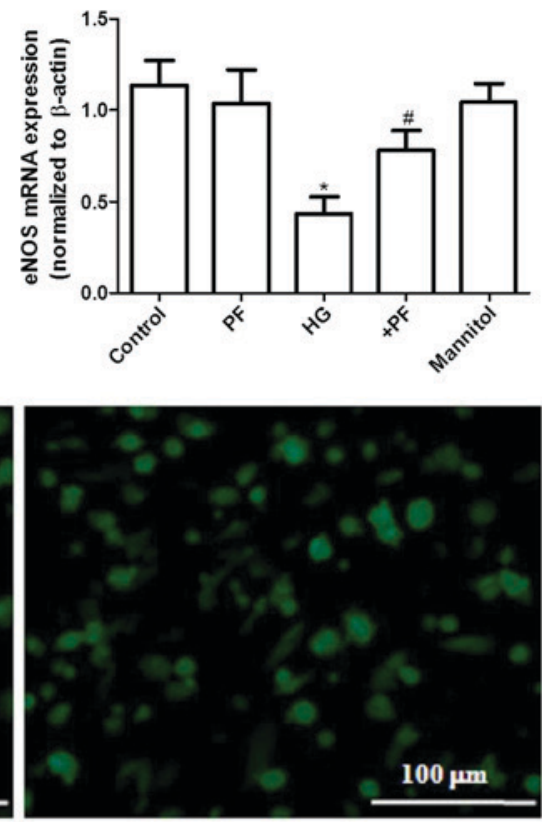

PF

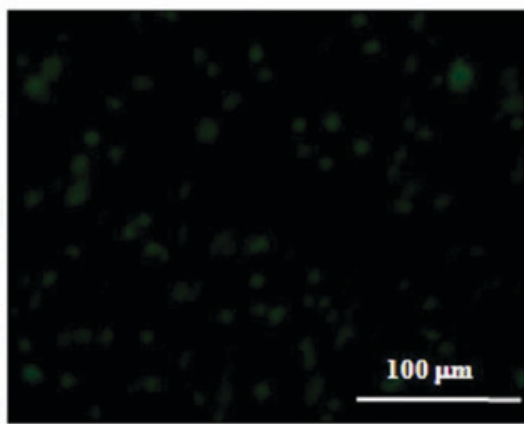

L-NAME
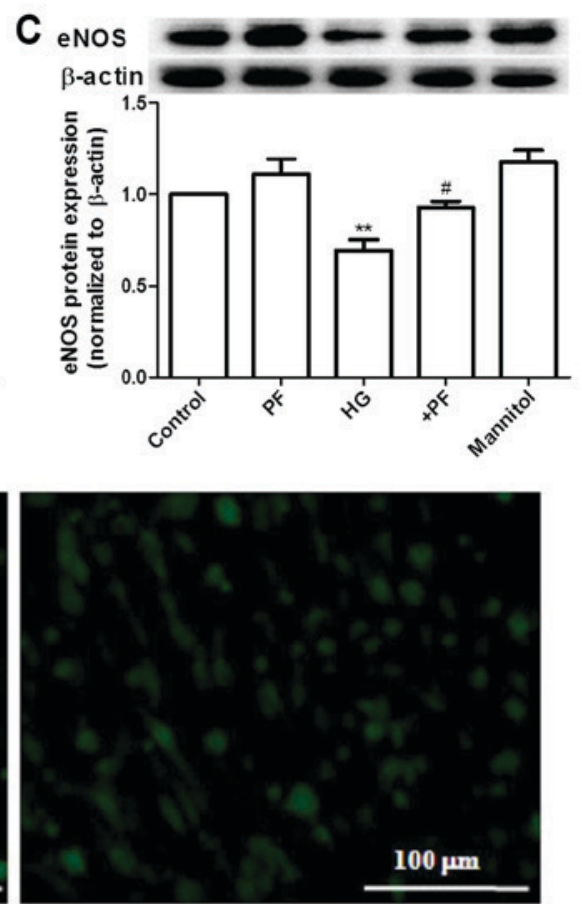

HG

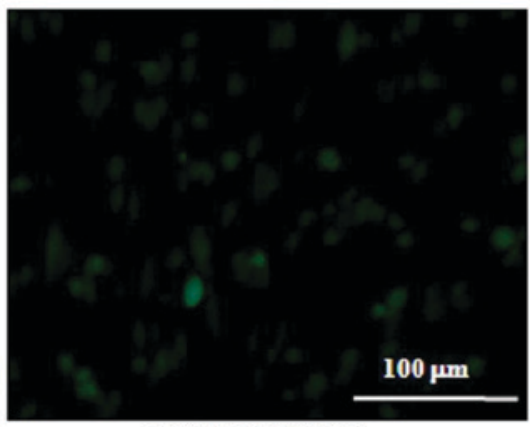

L-NAME+PF+HG

Figure 5. Effect of PF on eNOS expression levels in GEnCs treated with HG. (A) PF exerts no toxic effects on the cell viability of GEnCs. (B) eNOS mRNA expression levels in GEnCs. (C) eNOS protein expression levels in GEnCs. (D) Representative images of NO immunofluorescence staining in GEnCs. All values are expressed as the mean \pm standard error of the mean. $\mathrm{n}=3,{ }^{*} \mathrm{P}<0.05,{ }^{* *} \mathrm{P}<0.01$ vs. the control, ${ }^{*} \mathrm{P}<0.05$ vs. HG. PF, Piperazine ferulate; HG, high glucose; eNOS, endothelial nitric oxide synthase; N-nitro-L-arginine methylester (L-NAME).

\section{Discussion}

$\mathrm{DN}$ is a common condition that causes serious health issues worldwide. Glycemic control, blood pressure control and inhibition of the renin-angiotensin-aldosterone system have been demonstrated to reduce the incidence and delay the development of DN $(21,22)$. However, several patients with DN still progress to ESRD. Therefore, it is imperative to develop more effective therapeutic approaches to delay this disease. Proteinuria, or albuminuria, is considered a key marker of $\mathrm{DN}$, which is an independent risk factor for the development of kidney disease (23). Proteins that leak into the glomerular filtrate produce a toxic effect on tubular cells. Once tubular cells are damaged, interstitial fibrosis and inflammation will occur (24). In DN, renal function damage is also directly reflected by increased plasma levels of creatinine and urea nitrogen. In the present study, an STZ-induced diabetic nephropathy model was used to evaluate the effect of PF on the progression of DN. It was identified that PF significantly decreased 24-h albuminuria, creatinine and BUN levels in diabetic mice. Histological sections of kidney tissue demonstrated that PF alleviated the thickening of the basement membrane and inhibited mesangial matrix accumulation. These data highlighted that PF delayed the progression of DN. Furthermore, oxidative stress is involved in the development of diabetes complications. In the present study, the model control group exhibited an increase in the levels of MDA and a decrease in GSH-Px, SOD and catalase activities in the kidney tissues. Following administration of PF, a restoration of normal kidney oxidative stress levels was observed as MDA levels decreased and SOD, GSH-Px and catalase activities increased. It is worth noting that PF exerted no effect on blood glucose levels of diabetic mice and that the effect of PF on DN was independent of the blood glucose levels.

Dysfunction of endothelial cells contributes to the occurrence and development of DN, and NO is considered a potential therapeutic target (25). Renal GEnCs are a crucial component of the basement membrane. They regulate vasomotor tone, hemostasis and trafficking of leukocytes (26). GEnCs are part of the glomerular filtration barrier (GFB) and are used to 
prevent passage of macromolecules in the blood (27). eNOS regulates endothelial function and is involved in the development of DN (28). Diabetic eNOS knockout mice develop hypertension, albuminuria, mesangial matrix expansion and Kimmelstiel-Wilson nodules (29-31). The present in vitro study indicated that high glucose inhibited endothelial NO levels and eNOS expression and activity levels, which was reversed by pre-incubation of the cells with PF $(100 \mu \mathrm{M})$. Animal experiments further demonstrated that the model control group mice exhibited a significant downregulation of eNOS expression levels and that PF-treated diabetic mice demonstrated increased eNOS expression levels. These results are in line with previous reports that indicated significant downregulation of eNOS expression and activity levels in diabetic renal tissues $(28,32-34)$. However, it has also been reported that the expression of eNOS was upregulated in diabetic animals (35). The reason for this discrepancy is not yet clear. However, insulinopenia, the use of different animal models, the course of diabetes and other factors may be possible reasons leading to inconsistencies between the results of the present study and previous findings $(36,37)$. Taken collectively, the data suggest that PF can improve DN and that the mechanism is associated with the regulation of the NO levels and the eNOS expression levels of GEnCs.

Even though a lot of work has been done and useful information provided on treatment DN with PF in the current study, this study lacks in vivo experiments with eNOS knockdown mice to support the conclusions in the mechanism research. In addition, the effect of PF on the dysfunction of GEnCs induced by $\mathrm{HG}$ is the focus of the present study and there are no other available microvascular endothelia cell is suitable for the present study. So, only one type of endothelial cell was used to prove the conclusion in this study.

In conclusion, it was demonstrated that PF delayed the development of DN. The mechanism of action was associated with normalized expression and activity of eNOS. Future clinical studies are required to confirm the therapeutic effect of PF in patients with DN.

\section{Acknowledgements}

Not applicable.

\section{Funding}

The present study was supported by the Open-End Fund for the Valuable and Precision Instruments of the Central South University (grant no. CSUZC201734) and the National Natural Science Foundation of China (grant no. 81603171).

\section{Availability of data and materials}

All data generated or analyzed during the present study are included in this published manuscript.

\section{Authors' contributions}

YY and LS performed the experiments. JL analyzed the data and YY wrote the manuscript. LY and DX designed the experiments and revised the manuscript.

\section{Ethics approval and consent to participate}

The present study was approved by the Ethics Committee of Animal Experiments of the Central South University.

\section{Patient consent for publication}

Not applicable.

\section{Competing interests}

The authors declare that they have no competing interests.

\section{References}

1. International Diabetes Federation (IDF). IDF Diabetes Atlas 7th edition. 2017.

2. Balakumar P, Bishnoi HK and Mahadevan N: Telmisartan in the management of diabetic nephropathy: A contemporary view. Curr Diabetes Rev 8: 183-190, 2012.

3. Hsu YC, Lee PH, Lei CC, Ho C, Shih YH and Lin CL: Nitric oxide donors rescue diabetic nephropathy through oxidative-stress-and nitrosative-stress-mediated Wnt signaling pathways. J Diabetes Investig 6: 24-34, 2015.

4. Hiragushi K, Sugimoto H, Shikata K, Yamashita T, Miyatake N, Shikata Y, Wada J, Kumagai I, Fukushima M and Makino H: Nitric oxide system is involved in glomerular hyperfiltration in Japanese normo- and micro-albuminuric patients with type 2 diabetes. Diabetes Res Clin Pract 53: 149-159, 2001.

5. Chiarelli F, Cipollone F, Romano F, Tumini S, Costantini F, di Ricco L, Pomilio M, Pierdomenico SD, Marini M, Cuccurullo F and Mezzetti A: Increased circulating nitric oxide in young patients with type 1 diabetes and persistent microalbuminuria: Relation to glomerular hyperfiltration. Diabetes 49: 1258-1263, 2000.

6. Knott $A B$ and Bossy-Wetzel E: Impact of nitric oxide on metabolism in health and age-related disease. Diabetes Obes Metab 12 (Suppl 2): S126-S133, 2010.

7. Garsen M, Rops AL, Li J, van Beneden K, van den Branden C, Berden JH, Rabelink TJ and van der Vlag J: Endothelial nitric oxide synthase prevents heparanase induction and the development of proteinuria. PLoS One 11: e160894, 2016.

8. Nakayama T, Sato W, Kosugi T, Zhang L, Campbell-Thompson M, Yoshimura A, Croker BP, Johnson RJ and Nakagawa T: Endothelial injury due to eNOS deficiency accelerates the progression of chronic renal disease in the mouse. Am J Physiol Renal Physiol 296: F317-F327, 2009.

9. Liu Z, Pan J, Sun C, Zhou J and Li NA: Clinical effects of perazine ferulate tablets combined with eucalyptol limonene pinene enteric soft capsules for treatment of children with $\operatorname{IgA}$ nephropathy. Exp Ther Med 12: 169-172, 2016.

10. You GQ, Fu P, Xie XS, Liu F and Li J: Effects of piperazine ferulate on TGF-betal-induced renal interstitial fibroblast activation. Sichuan Da Xue Xue Bao Yi Xue Ban 39: 736-739, 762, 2008 (In Chinese).

11. Yin JP, Fu P, Xie XS, Liu F, Liu F and Zhou L: Effects of piperazine ferulate on connective tissue growth factor and extracellular matrix in TGF-betal induced mesangial cells. Sichuan Da Xue Xue Bao Yi Xue Ban 39: 732-735, 2008 (In Chinese).

12. Chakravarthy H, Beli E, Navitskaya S, O'Reilly S, Wang Q, Kady N, Huang C, Grant MB and Busik JV: Imbalances in mobilization and activation of pro-inflammatory and vascular reparative bone marrow-derived cells in diabetic retinopathy. PLoS One 11: e146829, 2016.

13. Saito T, Sumithran E, Glasgow EF and Atkins RC: The enhancement of aminonucleoside nephrosis by the co-administration of protamine. Kidney Int 32: 691-699, 1987.

14. Livak KJ and Schmittgen TD: Analysis of relative gene expression data using real-time quantitative PCR and the 2(-Delta Delta C(T)) method. Methods 25: 402-408, 2001.

15. Kanetsuna Y, Takahashi K, Nagata M, Gannon MA, Breyer MD, Harris RC and Takahashi T: Deficiency of endothelial nitric-oxide synthase confers susceptibility to diabetic nephropathy in nephropathy-resistant inbred mice. Am J Pathol 170: 1473-1484, 2007.

16. Prabhakar S, Starnes J, Shi S, Lonis B and Tran R: Diabetic nephropathy is associated with oxidative stress and decreased renal nitric oxide production. J Am Soc Nephrol 18: 2945-2952, 2007. 
17. Kamijo H, Higuchi $\mathrm{M}$ and Hora $\mathrm{K}$ : Chronic inhibition of nitric oxide production aggravates diabetic nephropathy in Otsuka Long-Evans Tokushima Fatty rats. Nephron Physiol 104: p12-p22, 2006

18. Qi H, Casalena G, Shi S, Yu L, Ebefors K, Sun Y, Zhang W, D'Agati V, Schlondorff D, Haraldsson B, et al: Glomerular endothelial mitochondrial dysfunction is essential and characteristic of diabetic kidney disease susceptibility. Diabetes 66 : 763-778, 2017

19. Boels MG, Avramut MC, Koudijs A, Dane MJ, Lee DH, van der Vlag J, Koster AJ, van Zonneveld AJ, van Faassen E, Gröne HJ, et al: Atrasentan reduces albuminuria by restoring the glomerular endothelial glycocalyx barrier in diabetic nephropathy. Diabetes 65: 2429-2439, 2016.

20. Broekhuizen LN, Lemkes BA, Mooij HL, Meuwese MC, Verberne H, Holleman F, Schlingemann RO, Nieuwdorp M, Stroes ES and Vink H: Effect of sulodexide on endothelial glycocalyx and vascular permeability in patients with type 2 diabetes mellitus. Diabetologia 53: 2646-2655, 2010

21. Gallagher H and Suckling RJ: Diabetic nephropathy: Where are we on the journey from pathophysiology to treatment? Diabetes Obes Metab 18: 641-647, 2016.

22. Kim Y and Park CW: New therapeutic agents in diabetic nephropathy. Korean J Intern Med 32: 11-25, 2017.

23. Hemmelgarn BR, Manns BJ, Lloyd A, James MT, Klarenbach S, Quinn RR, Wiebe N and Tonelli M; Alberta Kidney Disease Network: Relation between kidney function, proteinuria, and adverse outcomes. JAMA 303: 423-429, 2010.

24. Nolin AC, Mulhern RM, Panchenko MV, Pisarek-Horowitz A, Wang Z, Shirihai O, Borkan SC and Havasi A: Proteinuria causes dysfunctional autophagy in the proximal tubule. Am J Physiol Renal Physiol 311: F1271-F1279, 2016.

25. Cheng H, Wang H, Fan X, Paueksakon P and Harris RC: Improvement of endothelial nitric oxide synthase activity retards the progression of diabetic nephropathy in $\mathrm{db} / \mathrm{db}$ mice. Kidney Int 82: 1176-1183, 2012.

26. Ballermann BJ: Glomerular endothelial cell differentiation. Kidney Int 67: 1668-1671, 2005.

27. Lan L, Han Y, Ren W, Jiang J, Wang P and Hu Z: Advanced glycation endproducts affect the cytoskeletal structure of rat glomerular endothelial cells via the Ras-related C3 botulinum toxin substrate 1 signaling pathway. Mol Med Rep 11: 4321-4326, 2015.
28. Dellamea BS, Leitão CB, Friedman R and Canani LH: Nitric oxide system and diabetic nephropathy. Diabetol Metab Syndr 6: 17, 2014.

29. Nakagawa T, Sato W, Glushakova O, Heinig M, Clarke T, Campbell-Thompson M, Yuzawa Y, Atkinson MA, Johnson RJ and Croker B: Diabetic endothelial nitric oxide synthase knockout mice develop advanced diabetic nephropathy. J Am Soc Nephrol 18: 539-550, 2007.

30. Heeringa $P$, van Goor H, Itoh-Lindstrom Y, Maeda N, Falk RJ, Assmann KJ, Kallenberg CG and Jennette JC: Lack of endothelial nitric oxide synthase aggravates murine accelerated anti-glomerular basement membrane glomerulonephritis. Am J Pathol 156: 879-888, 2000.

31. Mohan S, Reddick RL, Musi N, Horn DA, Yan B, Prihoda TJ, Natarajan M and Abboud-Werner SL: Diabetic eNOS knockout mice develop distinct macro- and microvascular complications. Lab Invest 88: 515-528, 2008.

32. Koo JR and Vaziri ND: Effects of diabetes, insulin and antioxidants on NO synthase abundance and NO interaction with reactive oxygen species. Kidney Int 63: 195-201, 2003.

33. Sönmez MF and Dündar M: Ameliorative effects of pentoxifylline on NOS induced by diabetes in rat kidney. Ren Fail 38: 605-613, 2016.

34. Al-Rasheed NM, Al-Rasheed NM, Attia HA, Al-Amin MA, Al-Ajmi HN, Hasan IH, Mohamad RA and Sinjilawi NA: Renoprotective effects of fenofibrate via modulation of LKB1/AMPK mRNA expression and endothelial dysfunction in a rat model of diabetic nephropathy. Pharmacology 95: 229-239, 2015.

35. Sugimoto H, Shikata K, Matsuda M, Kushiro M, Hayashi Y, Hiragushi K, Wada J and Makino H: Increased expression of endothelial cell nitric oxide synthase (ecNOS) in afferent and glomerular endothelial cells is involved in glomerular hyperfiltration of diabetic nephropathy. Diabetologia 41: 1426-1434, 1998.

36. Komers R and Anderson S: Paradoxes of nitric oxide in the diabetic kidney. Am J Physiol Renal Physiol 284: F1121-F1137, 2003.

37. Ding Y, Vaziri ND, Coulson R, Kamanna VS and Roh DD: Effects of simulated hyperglycemia, insulin, and glucagon on endothelial nitric oxide synthase expression. Am J Physiol Endocrinol Metab 279: E11-E17, 2000.

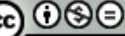

This work is licensed under a Creative Commons Attribution-NonCommercial-NoDerivatives 4.0 International (CC BY-NC-ND 4.0) License. 